\title{
Promoting Scientific Integrity in Nursing Research Part I: Current Approaches in Doctoral Programs
}

\author{
Elizabeth R. Lenz, PhD, RN, FAAN* and Shake Ketefian, EdD, RN, FAAN $\dagger$
}

\begin{abstract}
Schools of nursing with doctoral programs were surveyed to determine current approaches and elicit suggestions for institutional- and professional-level strategies to promote scientific integrity. Results from 38 schools are reported in a two-part series. Part 1 reports findings concerning formal and informal instruction about responsible science and the standards, norms, and guidelines being used to direct scientific inquiry. Information on misconduct and scientific integrity was typically included in required research methods, courses, and optional workshops, but the extent and scope of the instruction was variable, and a majority of respondents judged it to be marginal or inadequate. A high value was placed on informal student-mentor interaction. Where they existed, institutional guidelines were more specific than federal guidelines, but dealt primarily with procedures for handling alleged misconduct rather than for promoting responsible science. Findings suggest the need for a more proactive and consistent approach to promoting scientific integrity in doctoral programs. $J$ Prof Nurs 11: xx-xx, 1995. Copyright (c) 1995 by W.B. Saunders Company
\end{abstract}

$\mathrm{T}$ HE RECENT SPATE of highly publicized cases of scientific misconduct and the resulting investigations, sanctions, and law suits have given rise to a variety of policies and monitoring mechanisms at every level of medical research. Externally imposed regulations and formal rules and laws, rather than internalized ethics and integrity and informal norms regarding personal and professional responsibility, seem to be taking precedence as the arbiters of science. Although this trend is an understandable selfprotective reaction to documented and alleged in-

*Professor, School of Nursing, Senior Researcher, Center for Nursing Research, Hershey, PA.

†Professor, Director of Doctoral and Postdoctoral Studies, The University of Michigan, School of Nursing, Ann Arbor, MI

Address correspondence and reprint requests to Dr. Lenz: Center for Nursing Research, Hershey Medical Center, PO Box 850 , Hershey, PA 17033-0850.

An earlier version of this paper was presented by Dr. Lenz at the Scientific and Academic Integrity Conference, sponsored by the American Association of Colleges of Nursing, held in Arlington, Virginia, September, 1993.

Copyright (C) 1995 by W.B. Saunders Company

$8755-7223 / 95 / 1104-0006 \$ 3.00 / 0$ stances of misconduct, a positive proactive approach to encouraging responsible conduct in science can provide better guidance to those engaged in conducting and teaching science, thereby supporting positive conduct and, in effect, serving a preventive function (Sachs \& Siegler, 1993; Pritchard, 1993).

An effective proactive approach toward scientific integrity involves addressing it in the broadest sense; i.e., from the perspective of what constitutes good science and how one conducts science responsibly and honestly. It also involves teaching neophyte scientists not only about misconduct, but the appropriate principles and methods to be followed as well, along with the ethical issues involved (Sachs \& Siegler, 1993).

Scientific integrity needs to be viewed within the broad rubric of ethics. Although conceptions of nursing ethics have generally failed to embrace the realm of scholarship and have mainly dealt with biomedical, patient-related issues (Blancett, 1991) various areas of scholarship draw on and can be illuminated by reference to specific ethical principles. For example, in considering protection of human subjects, institutional review boards (IRBs) make judgments based on the duty of nonmaleficence and beneficence in assessing the risk-benefit ratio, the principle of autonomy, and the principles of justice (Munir \& Earls, 1992). Similarly, the areas of authorship credit and redundant publications raise such issues as the rights and responsibilities of all parties to access research data and the efficiency of resource use. The extent to which experienced and neophyte nurse scientists view scientific practice from such perspectives is not known.

The work of Merton (1968) has provided considerable guidance in viewing the practitioners of science as a community that sets norms to govern scientific activities. He identified four norms as the ethos of science that will provide the conditions for obtaining scientific truth: (1) universalism, the evaluation of scientific information independent of any knowledge of those who produce it; (2) communality, the avoidance of secrecy by making information public; (3) organized skepticism, the critical evaluation of all findings; and (4) disinterestedness, the pursuit of re- 
search without regard to self-interest ( $\mathrm{p}$ 613). As large amounts of public funds have been invested in research since Merton's analysis over 25 years ago, competition for funding has increased, science has become highly politicized, and policy makers have taken an unusual interest in the workings of science and scientists. Similarly, with the investment of private funds from proprietary groups in various research enterprises and academic scientific work, the possibility of a conflict of interest looms large. The environment in which scientists work is more complex than ever before, and a special degree of vigilance is needed to keep the values of science in the forefront of scientists' consciousness.

Within the framework of ethical principles and scientific community norms, responsibility for ethical conduct rests with the individual, regardless of what role or roles he or she occupies in the scientific community. In the conduct of science, integrity requires an awareness of one's biases, disclosure of limitations and sources of systematic bias and error, identification of the qualifications of one's arguments, meticulous documentation of data and evidence and making that information available to other scientists, fair treatment of co-workers, acknowledgment of financial support and assistance from students and others, commitment to intellectual diversity, and use of the standards of civility to govern reasoned discussion, thus making possible the fruitful exchange of knowledge and ideas (American Association for the History of Medicine, 1991). Formal and informal experiences afforded the scientist-in-training during doctoral education provide crucial underpinnings for subsequent conduct of science in an ethical and responsible manner.

The domain of scientific integrity is broad, encompassing such areas as data collection and management, authorship, peer review, the industrial-academic interface, oversight and training of neophytes, and relationships among colleagues. Although some principles and norms are common across the entire scientific enterprise, specific norms regarding aspects of scientific practice vary somewhat across disciplines, and even among specialties and sub-specialties within a given discipline. To date, little is known about the ways in which nurse scientists learn about scientific integrity, the content of the information they receive, or the formal guidelines and informal norms that guide the research conduct and related activities in the institutions in which they are prepared.

Given the considerable concern that is currently expressed in the scientific community at large about misconduct and the importance of promoting integrity among both experienced and neophyte scientists, a survey of nursing schools with doctoral programs was undertaken to determine current educational practices and possible strategies. The results are reported in this two-part series. The survey tried to answer the following questions: (1) what is currently being done to promote scientific integrity in those schools; (2) which guidelines, norms, and standards are currently used to direct scientific inquiry, and the types of oversight that exist; (3) which norms exist regarding authorship and publication practices; and (4) what strategies might be used to systematically promote scientific integrity within schools of nursing and within the profession as a whole. Part I addresses questions 1 and 2 , and part II will address questions 3 and 4.

\section{Method}

To gather the information to answer these questions, an open-ended 21-item questionnaire was developed and mailed to the dean or chief administrative officer of each of the 54 nursing schools with a doctoral program that was included on the Department of Health and Human Services (DHHS)-Division of Nursing's 1992-1993 listing. The dean was asked to pass the questionnaire on to the individual in charge of the doctoral program and another individual who might be able to answer the questions on behalf of the school as a whole. Respondents from each school could collaborate in answering the questions. To facilitate and encourage responses, respondents were also permitted to choose between written responses to the questions or a phone interview; four chose phone interviews. Within 4 weeks of distribution, we received responses from individuals representing 38 schools. In most cases only one person responded; in six cases, two individuals responded. The respondents who identified their positions numbered as follows: 24 associate deans (academic and/or research); eight doctoral program directors; seven faculty; two IRB chairpeople; one university grants administrator. Two respondents did not indicate their positions.

In constructing the questionnaire, the focus was on scientific integrity rarher than misconduct. Questions dealt with teaching approaches with regard to specific issues, socialization mechanisms, use of guidelines, role of various agents as actual or potential oversight bodies, publication practices, and suggested strategies for promoting scientific integrity. We purposely supplied no definition of scientific integrity. As a result, 
responses reflected different interpretations. Some respondents limited their replies to matters concerning the rights of human research subjects, whereas others took the broader view that is consistent with the one that is reflected in the literature.

The responses to the questions were tabulated and will be described. There was much variation; however, a few patterns emerged. In reporting the results, the focus will be on trends in the data rather than on a full presentation of the responses. Because we were looking for ideas of what was operational within nursing programs, we chose the school rather than the respondent as the unit of analysis. For the schools with two respondents, the two responses were compared to determine if they were consistent, and one combined response was formulated and used for tabulation purposes.

Within the questionnaire, two questions dealt with master and undergraduate level instruction, but those results are not reported here because the focus of this series is on practices with regard to doctoral programs, faculty, and overall institutional strategies.

\section{Results}

\section{Instruction Regarding Scientific Integrity}

Most schools reportedly engage in several different means of communicating with doctoral students

TABLE 1. Formal and Informal Instruction Regarding Scientific Integrity in Doctoral Programs

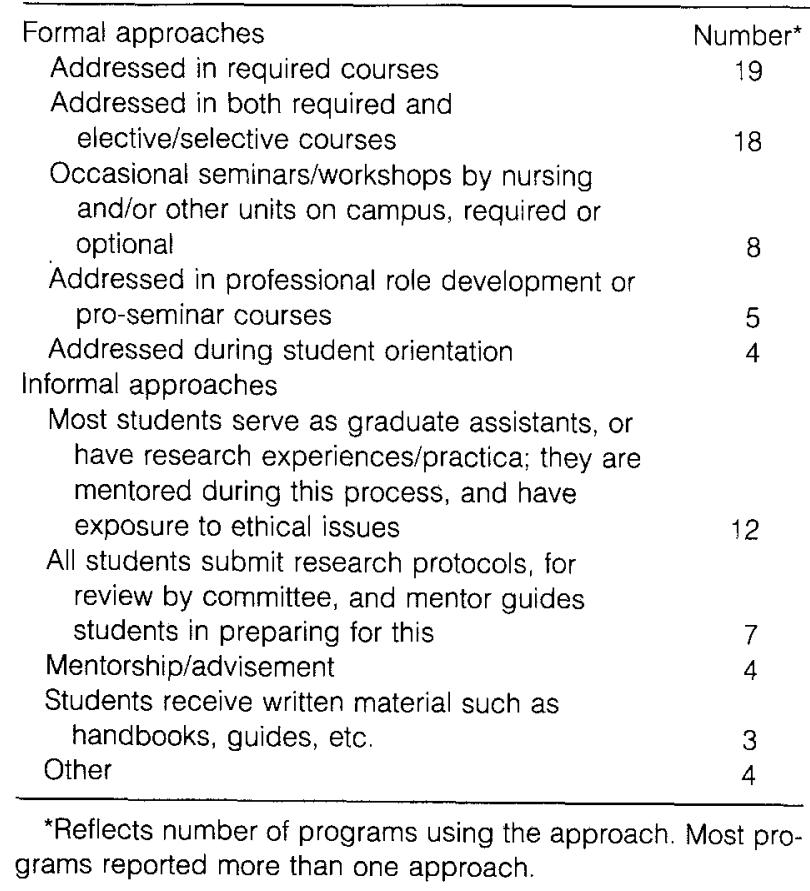

about scientific integrity. Table 1 presents a listing of formal and informal methods of instruction used. The type of formal instruction that was reported most often was either to include the content in required research methodology or other courses $(n=19)$ devoting 2 to 12 hours to it, or to include it in both required and elective courses $(n=18)$. In two schools, entire courses were devoted to the topic. Professional seminars were also identified as the place where integrity and ethics were discussed; in a few instances, required or elective seminars contained information on dissertation development and the professional researcher's role. Some respondents also indicated that ethical issues, particularly those related to the use of vulnerable populations in research, are addressed in substantive clinical courses. Four schools provided information on ethical conduct in science during student orientation.

Other formal offerings that were reported include half-day or day-long programs presented at the campus or medical-center level by the graduate school, the institutional IRB, or by groups of schools or departments working together $(n=8)$. In part, these campus-level offerings were created in response to the 1990 federal mandate that students receiving $\mathrm{Na}$ tional Research Service Awards (NRSAs) also receive regular instruction regarding scientific integrity and misconduct. Typically, these programs are mandatory for students on NRSAs; for others, attendance is optional.

A few sample course syllabi for elective or required courses addressing scientific integrity were provided by respondents. Sometimes detailed content was explicit on the syllabus, and sometimes, only broad headings were identified. One category evident on syllabi was misconduct: definitions of misconduct, sample cases of alleged misconduct, factors that promote integrity and prevent misconduct; and relevant governmental, funding agency, and institutional policies and procedures, including those for handling allegations of misconduct (also whistle blowing, rights of the accused, etc). Other topics include protection of human and animal subjects in research; the scientist/ researcher role and its attendant rights and responsibilities, including discussion of sound laboratory practice, data management and interpretation; collaboration in research and the attendant role relationships among investigators; subject/investigator relationships; and responsibilities of reviewers of grants and manuscripts. Conflict of interest as it relates to grant review and research funding was also addressed. Another set of topics addressed authorship and publica- 
tion practices, including aliocation of credit and multiple publications.

Several useful source materials were mentioned, including "On Becoming a Scientist" (National Academy of Sciences), "Honor in Science" (Sigma Xi), "The Responsible Conduct of Research in the Health Sciences" (Institute of Medicine), "Responsible Science" (National Academy of Sciences), and the videotape of a Public Broadcasting System "Nova" program entitled "Do Scientists Cheat?" Several institutions distributed locally produced resources and guidelines as well.

Informal instruction in matters of scientific integrity is reported to take place primarily in one-on-one situations or small groups with research advisors and mentors. In several programs students are required to complete a research residency practicum of one or more semesters. During those hands-on experiences, students receive instruction or have the opportunity to observe research ethics in practice. This was believed to be a very valuable experience, and one that encourages open discussion of data and their interpretation, thereby serving to prevent sloppy or fraudulent practices.

Much of the informal instruction concerning ethical research conduct occurs in the context of the dissertation research project; thus, there was virtually unanimous mention of the student's research advisor or mentor as key in informal instruction. The mentor is seen as having the responsibility to discuss issues with the student, guide the student through necessary approvals, and review any manuscripts produced by the student. Other informal means mentioned were discussions at faculty meetings, journal clubs and brown-bag lunches with the doctoral program director, research office director, or school representative to the IRB.

Many respondents believed that the responsibility for socializing students as researchers should be performed informally by the research advisor or mentor, rather than formal school instruction. Nearly as many respondents indicated that an equal emphasis on the two approaches (formal and informal) was desirable. Schools noted that the advantage of formal instruction was consistency in the message delivered, and the assurance that all students would receive specified content, whereas the advantages of the informal approach was its specificity, tailored as it is to the student's needs. A drawback noted to the informal approach was that the message each student would get was a function of the specific faculty mentor's beliefs, experiences and biases.

\section{Faculty Development in Scientific Integrity}

Given the emphasis on faculty in socializing students through both formal and informal means, it was important to determine what types of experiences were offered to faculty. A combination of formal and informal approaches was mentioned. Here too, considerable variation existed with respect to areas of instruction provided and whether it was mandatory or discretionary. Respondents from 11 schools noted that there was either no or only informal training or nothing at all provided for the faculty, whereas in one school faculty were required to attend at least one seminar per year, the outline for which had been approved at the institutional level. More commonly, faculty were invited but not required to attend the formal programs mounted for students $(n=10)$, hold discussions at faculty meetings and use other informal situations $(n=11)$, or receive periodic updates of changes in policies through newsletters or memoranda in = 7).

A majority of responses suggested that updates for faculty tended to address human subject issues rather than scientific integrity from a broader perspective. Some exceptions were notable. In three institutions, workshops were offered on teaching scientific ethics to students. In 14 instances people would seek out available resources or serve on a related campus committee such as the institutional IRB, Animal Use Committee, or the university committee on ethical issues in computer and software use-the only mention of this area of integrity. Such experiences were deemed very valuable for instructing faculty about the many aspects of scientific integrity. Stressing the importance of collegial interaction, one respondent noted that the most effective preventive activity is faculty participation in research group meetings and peer review sessions in which grant proposals are prereviewed and issues discussed.

\section{Adequacy of instruction}

Respondents were asked to judge the adequacy of the instruction provided to students and faculty. Ileven respondents judged it to be adequate or more than adequate. A few of these respondents indicated that their schools had a strong and pervasive commitment to ethics in a generalized sense not limited to research ethics. Fourteen respondents were not satisfied with the instruction offered by their institutions and deemed it marginal or inadequate. Some gave equivocal answers, indicating that the instruction was adequate, but stated that, because attendance was dis- 
cretionary, many did not access the available resources, especially those who needed them most.

Where judgments of inadequacy were made, institutions identified areas needing attention. Those areas mentioned were the following: (1) authorship credit issues, both in relation to publications with faculty colleagues and with students; (2) data management and storage; (3) data ownership; (4) accurate reporting of data; and (5) plagiarism, specifically, failure to provide appropriate citation for others' work. The latter was mentioned as a particularly difficult issue in working with international students. There are considerable cross-cultural differences in citation practices. For example, in some cultures, it is considered a mark of respect to quote and make extensive use of another's words without including explicit citations.

\section{Use of Guidelines and Norms}

One question posed regarded the use of published guidelines for clinical and laboratory research in the school and institution. Respondents cited federal guidelines the most often (28 schools). Institutional guidelines were reported in 16 schools, and when samples were provided, they were found to be more specific and more stringent than the federal guidelines. Professional standards, such as those set forth by the ANA and the American Association of Medical Colleges, or the standards and procedures recommended in textbooks were also mentioned, as were the guidelines provided by the state or other sponsoring agencies. Seven respondents reported having no formal guidelines.

\section{Institutional Oversight}

When asked about the type of institutional oversight that exists to monitor faculty and student adherence to standards of sound ethical research practice, the most frequent pattern of oversight was one in which the institutional IRBs $(n=22)$, and in a few instances the School of Nursing's research office, perform the initial review of a project, then conduct annual reviews of progress. This oversight is generally limited to the human or animal rights provisions of the research and does not monitor other aspects.

Responsibility for ongoing oversight of the conduct of research by faculty and students was generally said to be by individuals who are close enough to the activity to remain informed about what is actually happening. Examples cited included the department chairperson, the principal investigator of the project and the research group, and, in the case of student research, the faculty advisor or mentor. In some cases, administrative oversight was limited to fiscal and procedural requirements, and did not include adherence to scientific standards. Reactions against the idea of oversight were expressed by two respondents: one wanted to avoid the stance of policing and the other indicated that, although monitoring adherence to guidelines had been discussed by the faculty, there was opposition to the idea. In eight instances, no oversight mechanism was identified.

\section{Discussion}

In 1989, the Institute of Medicine's Committee on the Responsible Conduct of Research cited a lack of formal training in scientific ethics and the responsible conduct of science as a deficit in the training of scientists and clinicians (Institute of Medicine, 1989). Since that time, partially in response to federal mandates, most institutions preparing scientists have made provisions for at least some formal educational experiences. The present survey results indicate that virtually all nursing schools offering doctoral programs provide some formal instruction in scientific misconduct and integrity; however, these experiences vary tremendously in size and scope. The range went from schools required attendance at courses that fully explored the practice of responsible science to institutions that placed an occasional mention of selected aspects of scientific integrity in required or elective research methodology courses. At one end of the continuum were schools whose only formal effort is to ask, but not require, doctoral students to attend an annual IRB workshop or to include in their research courses a minimal amount of information about the protection of subjects and data management. At the other end were those schools in which ethical considerations are pervasive and are addressed in many ways throughout every faculty member and student's tenure.

The few schools reporting an availability of extensive formal instruction in scientific integrity tended to be those with a strong philosophical commitment to ethics or with individual faculty members of multidisciplinary groups of faculty who, because of their considerable interest in the topic, go well beyond the minimum regulation requirements to develop comprehensive learning experiences for students. The most comprehensive offerings tended to be at institutional or multidepartmental levels, rather than just at the nursing and faculty level. This pattern not only eliminates duplication, but allows students to benefit from multiple perspectives and domains of expertise. 
Several issues were included in courses and workshops with a high degree of consistency: definitions, examples and possible causes of misconduct; institutional procedures for handling allegations of misconduct; and the rights and protection of human subjects. Less frequently included were some of the more positive responsibility-generating topics, such as: the ethical principles, norms and procedures involved in responsible science; norms of collegial interaction; the roles and pressures and values in the scientists' behavior; and specific strategies for preventing inadvertent errors that might deviate from accepted practice.

In describing the benefits of a formal comprehensive course in scientific integrity, Sachs and Siegler (1993) emphasized the value of open debate and exchange of ideas for clarifying definitional issues and sensitizing scientists-in-training to areas of potential ethical conflict. The current findings suggest that, with a few exceptions, nursing's future scientists are not being afforded such broadly scoped and wellplanned opportunities in their doctoral programs. Rather, in many instances their exposure to the teaching of scientific integrity is unsystematic and dependent on the interest, expertise, and values of the individual faculty members who teach required methodology courses. Perhaps because they have been so idiosyncratic to date, formal approaches to teaching scientific integrity were deemed less valuable than informal experiences by many respondents.

The importance of informal instruction was repeatedly emphasized. The student's mentor or research advisor was said to provide ongoing guidance, particularly during the dissertation research experience. Such informal instruction was believed by many to be critical for socializing students as researchers and familiarizing them with the norms and values that are specific to nursing science. The faculty/student relationship was repeatedly highlighted as the critical nexus in teaching scientific integrity, and, indeed, in all of doctoral education. However, it was readily acknowledged that students' informal exposure to the norms and practices of responsible science tends to be variable. Factors undoubtedly contributing to this variability include differences in mentors' belief systems, disciplinary backgrounds and styles of working with students, as well as differences in the levels of both students' and mentors' involvement in research that represents good science, and the nature of the institution's research environment. In an educational approach that virtually places total reliance on the student/mentor relationship to communicate the norms and practices of responsible science, a number of issues can be raised about the adequacy of the experience, particularly for part-time students whose exposure to the scientific enterprise may be limited and sporadic.

A major concern stems from the finding that the faculty's state of preparedness in matters of scientific integrity was less than adequate, with their access to available learning opportunities and resources discretionary and often underutilized. The effectiveness of informal methods and peer interactions for dealing with these issues could not be assessed, but the majority of respondents judged current efforts at formal instruction to be marginal or inadequate, and generally less adequate for faculty than for students. In many institutions faculty are helped little by existing guidelines, policies, and procedures, because they are either extremely broad and general, subject to considerable diversity in interpretation, or are limited almost entirely to procedures that must be followed if misconduct is alleged. Vagueness may be of particular concern to those faculty who are being asked to mentor doctoral students but who may have had less than optimal mentoring themselves, or to faculty trying to work with students whose cultural norms differ from their own.

In this study, scientific integrity was conceptualized from a broadly encompassing perspective. In many of the responses the emphasis appeared to be on the protection of research subjects' rights, betraying a rather limited understanding of the scope of scientific integrity. To some extent, some respondents' limited perspective may reflect the equally limited perspective of institutional policies and oversight procedures. The main formal oversight body seemed to be the institution's IRB, a mandatory control for institutions receiving federal grants and contracts. In most of these cases, the main task of the IRB was to review proposals for human subjects' protection rather than ongoing monitoring. The main publication standard used was the APA Manual, mostly for proper format. In addition, sample materials provided, along with respondents' comments, showed that where institutional policies existed, they dealt primarily with procedures for handling scientific misconduct rather than providing positive guidance in the proper practices in science. This picture suggests that institutions seem to be acting in response to external mandates, and worrying about the occurrence of negative behavior on the part of scientists, rather than creating a positive institutional climate for promoting desirable practices.

Educational efforts, information support for administrators, and the development of standards for ethical 
conduct in research are all important institutional responsibilities that set a climate that affects all those working within the institution, and communicate messages about the commitment of the institutional leadership or lack thereof (Gunsalus, 1993). The presence of policies and adherence to them supports patterns of behavior that advance the purpose of scientific activity and the ends of science (Pritchard, 1993). Therefore, it is suggested that academic administrators and faculties make concerted efforts to develop a plan to assure greater faculty awareness about the issues of scientific integrity and ways in which such content might be taught to doctoral students.

Policies and practices of scientific integrity concern the cultivation of good conduct in science, and aim to promote soundness of scientific practices in general; these good practices are designed to lead to the development or application of generalizable knowledge. Keeping in mind the ends and ideals of science helps provide ways of refining the various elements of good scientific conduct (Pritchard, 1993). Scientific achievement, in part, depends on how ethically the science was conducted. Pritchard (1993) further contends that policies are intended to provide institutional support for behaviors that promote good science. A commitment to scientific ideas in neophytes needs to be developed during the socialization process, while these neophytes are in doctoral study.

The survey findings suggest the need for a more active and consistent approach to the teaching and practice of various elements of scientific integrity, whether they be formal or informal approaches. As a result of pressure from grant sponsors (mostly governmental), universities have developed procedures for investigating cases of alleged misconduct; they appear to have left up to the scientists and local units the decision of what must be taught and practiced during the conduct of science. In the absence of clear and institutionally accepted policies, the result appears to be highly variable and inconsistent, with research teams or even individual mentors passing on practices according to their own views of what is important.

Sachs and Siegel (1993) have eloquently underscored the importance of teaching scientific integrity in a recent paper: "If we rely on rules, guidelines and regulations to address issues of scientific integrity, we will lose the benefits that a serious educational approach offers. If we fail to take responsibility for training young investigators in the responsible conduct of research, we are likely to invite increased external oversight, inspection, and even control of scientific training and perhaps of the practice of science itself" (p 875).

\section{References}

American Association for the History of Medicine, Report of the Committee on Ethical Codes. (1991). Ethical codes concerning historical research. Bulletin for the History of Medicine, 65, 565-570.

Blancett, S. S. (1991). The ethics of writing and publishing. Journal of Nursing Administration, 21(5), 31-36.

Gunsalus, C. K. (1993). Institutional structure to ensure research integrity, Academic Medicine, 68, Suppl 3, S33-S38.

Institute of Medicine (1989). The responsible conduct of research in the bealth sciences. Washington, D.C: National Academy Press.
Merton, R. K. (1968). Social theory and social structure. New York, Free Press: 608-615.

Munir, K., \& Earls, F. (1992). Ethical principles governing research in child and adolescent psychiatry. Journal of American Academy of Child and Adolescent Psychiatry, 31(3), 408-414.

Pritchard, I. A. (1993). Integrity versus misconduct: Learning the difference between right and wrong. Academic Medicine, 68, Suppl 3, S67-S71.

Sachs, G. A., \& Siegler, M. (1993). Teaching scientific integrity and the responsible conduct of research. Academic Medicine, 68, 871-875. 